\title{
Trabalhando os conceitos de dilatação temporal e contração espacial para alunos de baixa visão
}

Working the concepts of temporal dilation and spatial contraction for low vision students

\author{
E. R. Granhen ${ }^{1 *} ;$ E. da C. Sobral ${ }^{2}$ \\ ${ }^{1}$ Faculdade de Física/ICE, UNIFESSPA, 68505-080, Marabá-Pará, Brasil \\ ${ }^{2}$ Programa de Pós graduação em Ensino de Física/Polo-29/FAFIS-ICE, UNIFESSPA, 68505-080, Marabá-Pará, \\ Brasil \\ *granhen@unifesspa.edu.br
}

(Recebido em 27 de fevereiro de 2019; aceito em 09 de maio de 2019)

\begin{abstract}
Este trabalho tem a intenção de compartilhar a experiência de ensino dos conceitos de dilatação temporal e contração espacial, presentes na Relatividade Especial de Einstein realizadas com uma aluna que apresenta uma deficiência visual conhecida como retinose pigmentada, de acordo com a transcritos no Relatório Oficial do IV Congresso Brasileiro de Prevenção da Cegueira, que classifica retinose pigmentada como baixa visão. Para abordar estes conceitos desenvolvemos experimento-atividades para explica-los a este público, em especial, alunos de baixa visão, contando para isso, com o relato da própria estudante.
\end{abstract}

Palavras-chave: Baixa visão, Relatividade Restrita, Ensino inclusivo.

This work intends to share the teaching experience of the concepts of temporal dilation and spatial contraction, present in the Special Relativity of Einstein, performed with a student with a visual deficiency known as pigmented retinosis. According to transcribed in the Official Report of the Fourth Brazilian Congress on the Prevention of Blindness, which classifies pigmented retinosis as low vision, in order to approach these concepts, we developed experiment-activities to explain them to this public, especially, lowvision students, counting for this, with the student's own report.

Keywords: Low vision, Restricted Relativity, Inclusive teaching.

\section{INTRODUÇÃO}

A maioria dos alunos durante sua temporada no Ensino Médio (EM) não tem contato com o conhecimento acerca do tema da Relatividade especial, ademais quando se trata de alunos com algum tipo de deficiência. Motivados por este desafio, propusemos dois experimentos e algumas atividades para que possamos passar a ideia sobre dilatação do tempo e a contração do espaço, conceitos da relatividade que mesmo para o aluno com melhor rendimento já é complexo, mas aqui apresentaremos uma metodologia que se propõe a repassar estes conceitos para ambos os públicos.

O professor Wilson Coeicev, que tem vasta experiência na área de Saúde Coletiva com ênfase em Optometria e Especialização em Baixa Visão, resume bem e de maneira muito simples o conceito de baixa visão: "baixa visão se aplica aos casos que, com a melhor correção, tenha ainda no máximo $30 \%$ de visão normal, mesmo com o uso de lentes convencionais, ou após tratamento clínico e/ou cirúrgico, utilizando recursos visuais para leitura e escrita" [2]. Sob um olhar pedagógico, Conde (2005) [3] define Baixa Visão (BV) como a condição de visão de um "portador de visão subnormal que lê tipos impressos ampliados ou com o auxílio de potentes recursos ópticos". Esses casos, muitas vezes, são negligenciados visto que a deficiência não é tão visível ao olho do outro.

Dentre as doenças que causam baixa visão alguma delas são a retinocoroidite macular por toxoplasmose, a retinopatia da prematuridade, a catarata congênita, a retinose pigmentar a atrofia óptica, o albismo e o glaucoma [4].

Segundo Soranz et al. (2016) [5] "a retinose pigmentar (RP) é a forma mais comum das distrofias hereditárias da retina, afetando $4 \%$ da população mundial. É caracterizada pela progressiva degeneração da retina, com acometimento de fotorreceptores e epitélio pigmentar". Tayah et al. (2004) [6] afirmam que o quadro típico é "caracterizado por dificuldade inicial de adaptação ao escuro, chegando à cegueira noturna, com perda do campo visual periférico ainda na adolescência, 
o que pode se agravar levando à deterioração da visão central, podendo ocorrer a cegueira, em alguns casos, aos 30 anos". No Brasil estima-se que existam mais de 1.200.000 deficientes visuais. Segundo Furtado et al. (2015) [7]. Dados da Organização Mundial de Saúde indicam que aproximadamente 6 a cada 10 dos casos são classificadas como cegueiras evitáveis, ou seja, poderiam ter sido tratados. Os casos de retinose pigmentar (RP) encontram-se dentro dos $40 \%$ restantes, que compreendem os casos de cegueiras inevitáveis (Figuras 1 e 2).

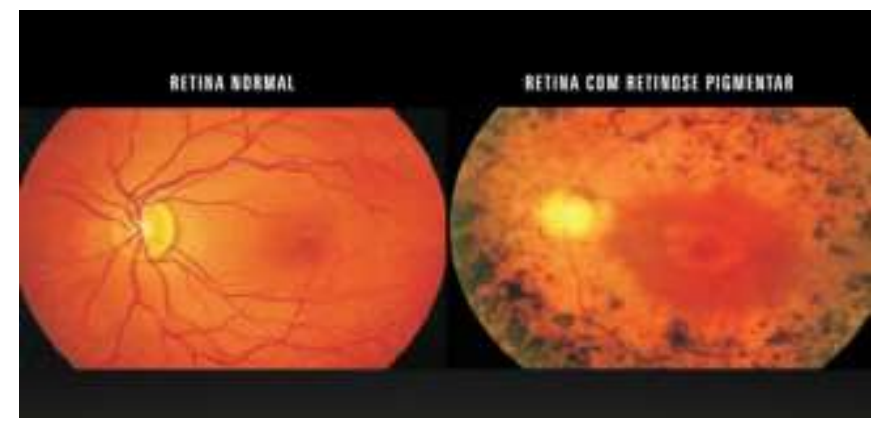

Figura 1: Imagens comparativas da retina de um olho com normal e um olho com retinose. Fonte: Furtado et al. (2015) [7].
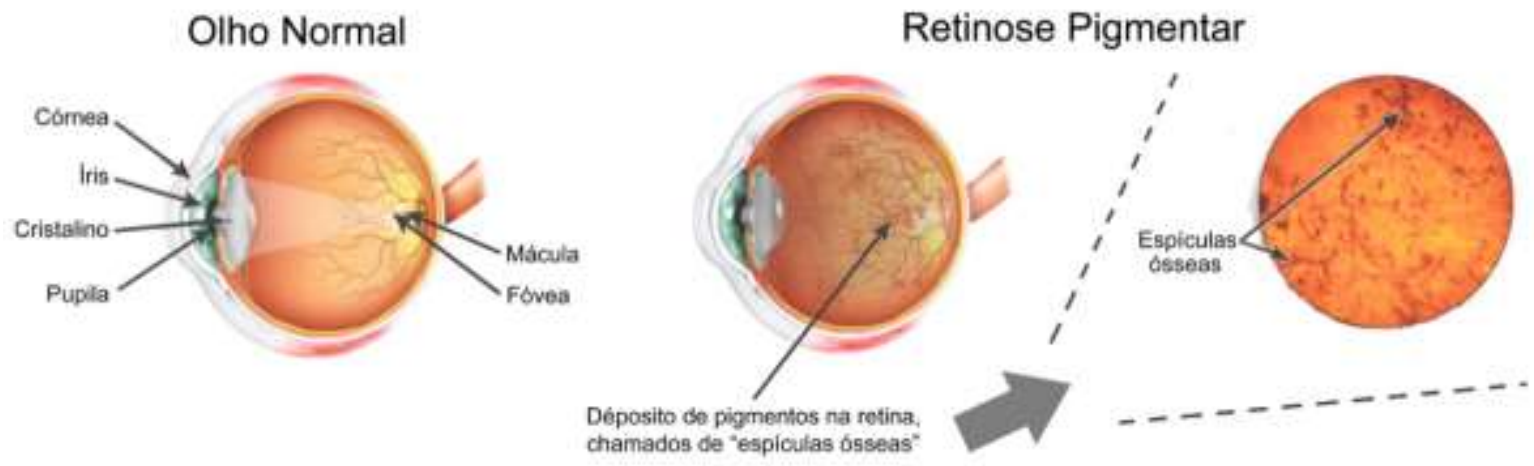

Figura 2: Padrão de distribuição dos depósitos de pigmentos retinianos, característico de uma retina saudável e de uma retina com retinose pigmentar. Fonte: Furtado et al. (2015) [7].

\section{MATERIAL E MÉTODOS}

A nossa pesquisa é do tipo qualitativa sobre método de um estudo de caso que, segundo Sturman (1997) [1], é um termo genérico para pesquisa de um indivíduo, um grupo ou um fenômeno. Nosso estudo tem como objetivo alcançar o maior número possível de estudantes diagnosticados com Baixa Visão, mas com um número realmente limitado de participantes devemos manter reservada algumas informações como local de estudo, nome e idade, mas o TCLE (Termo de Consentimento Livre e Esclarecido), obrigatório em pesquisas dessas circunstâncias, foi assinado pela aluna. A proposta de ensino abordando o tema Relatividade atende à reformulação do projeto de Curso de Técnico de Meio Ambiente, na forma Integrada ao ensino médio, em uma das Instituições de Ensino Federal (IEF). Acompanhamos a aluna E.A.C, 16 anos, que possui retinose pigmentar e participou da pesquisa, sempre acompanhada por uma professora que a auxilia nas atividades. Todo o trabalho teve como prioridade atender suas necessidades quanto a sua limitação visual.

Durante a produção do trabalho, E.A.C. nos informou que tem muita dificuldade com os cálculos pois não consegue enxergar o todo de uma equação e de figuras geométricas: “...fica como se fosse um quebra cabeça e não dá para juntar". Por conta disso, tivemos que buscar uma metodologia que pudesse contemplar esse desafio. A aluna também falou que gosta de desafios e sempre que as aulas teóricas de física são propostas ela se identifica mais.

Seu olho se movimenta quase que o tempo todo tentando achar o foco. Em um dos nossos encontros entregamos uma fita métrica para que ela tentasse descrever em centímetros o seu campo 
visual, colocando um letreiro a uma distância equivalente a distância de seus braços esticados. Com muita dificuldade, ela chegou à $10 \mathrm{~cm}$, ou seja, o que ela conseguiria ler ou perceber o que estivesse escrito, seria algo que estivesse dentro desse espaçamento de $10 \mathrm{~cm}$ à uma distância equivalente à de seus braços esticado (ver Figura 3). Segundo a mesma, seus olhos enxergavam, mas não definiam o entorno, caso precisasse movimentar os olhos para focar nos pontos interiores da figura, estes também se embaçavam.

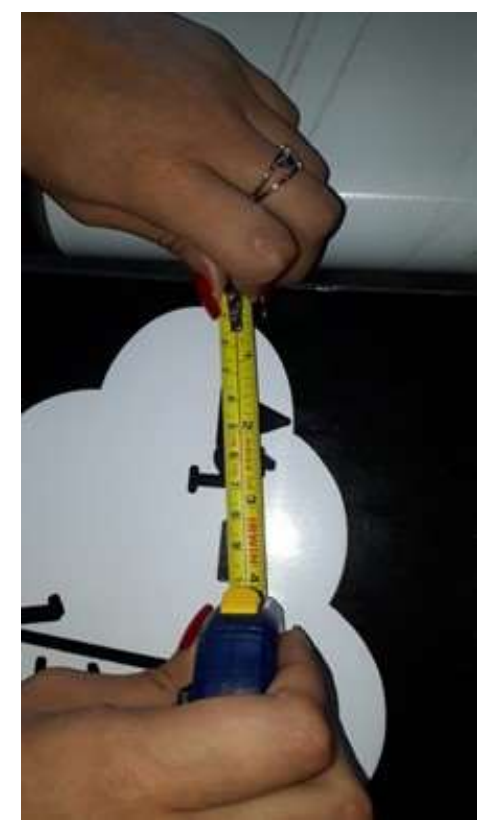

Figura 3: Campo visual da aluna E.A. C. Fonte: Os autores.

Apresentamos duas experiências acerca do tempo e do espaço. Na primeira experiência apresentamos o que vamos chamar de Tela da dilatação temporal, ou somente Tela, e a outra chamaremos de Rede da contração espacial, ou somente de Rede. Como vamos explicar a seguir, estas experiências foram construídas com o intuito de abordar ludicamente os conceitos da relatividade especial, mais precisamente da dilatação temporal e da contração espacial, para o público com baixa visão.

\subsection{TELA DE DILAÇÃO TEMPORAL}

O conceito de dilatação temporal na Relatividade Especial pode ser estudado em muitos livros básicos de Física no curso de graduação, usamos um livro muito comum nos cursos de Exatas e Engenharia que é o Fundamentos de Física, volume 4, de autoria de Halliday et al. (2009) [8]. De acordo com o que é descrito sobre a Teoria de Einstein a cerca da dilatação temporal no livro do Halliday é preciso que se faça a seguinte observação a respeito dos observadores,

se dois observadores que estão se movendo um em relação ao outro medem intervalor de tempo (ou sepração temporal) etre dois eventos, em geral encontram resultados diferente. Por que? Porque a separação espacial dos eventos também pode afetar o intervalo de tempo medido por estes observadores, ou seja, o intervalo de tempo entre dois eventos depende da distância entre os eventos, tanto no espaço como no tempo, e a separação espacial e temporal são interdependentes.

Dito isso o conceito para dilatação temporal pode ser colocado da seguinte forma:

Quando dois eventos ocorrem no mesmo ponto de um referencial inercial o intervalode de tempo entre os eventos, medido no referencial, é chamado de intervalo de tempo próprio ou tempo próprio. Quando esse intervalo de tempo é medido em outro referencial o resultado é sempre maior que o intervalo de tempo próprio. 
Para construir o nosso raciocínio, usamos o exemplo do livro em que os observadores João e Maria fazem a medição de um evento que se dá no interior do vagão de um trem. É considerado que o observador Maria, que se encontra em repouso dentro do vagão do trem, faz a medição do intervalo de tempo que um pulso luminoso, emitido dentro do vagão, deve fazer. Este pulso parte de uma fonte do chão para o teto e é refletida num espelho que se encontra no teto, o pulso refletido retorna ao chão é medido em um detector no chão. Já o intervalo de tempo medido pelo observador João, que se encontra fora do trem e em repouso na plataforma de uma das estações, de acordo com o que diz a teoria da relatividade especial de Einstein, é diferente do intervalo medido pelo observador Maria, e estes tempos estão relacionados entre si por um fator conhecido como fator de Lorentz, como mostraremos a seguir. Na Figura 4 apresentamos resumidamente o exemplo.
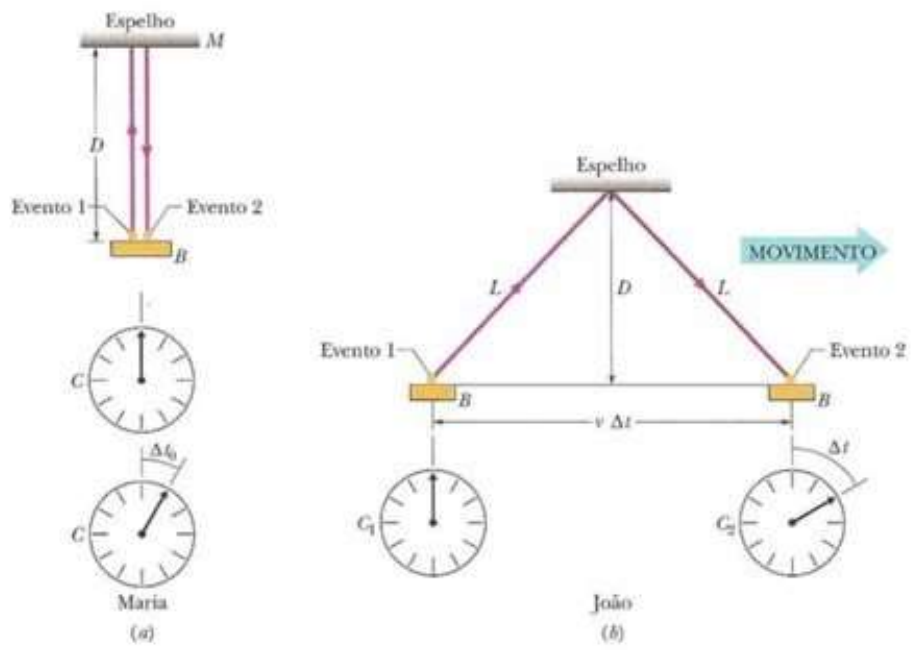

Figura 4: Em (a) Maria mede o intervalo de tempo que chamamos de tempo próprio e em (b) o intervalo de tempo medido por João. Retirado de Halliday et al. (2009) [8].

A Tela é o nosso dispositivo que deve dar a ideia sobre o conceito de dilatação temporal, ela tem o formato de uma mesa, e nela uma tela com a figura de uma nave espacial desenhado em uma lona que deve passar por dois cilindros giratórios, estes cilindros estão conectados a um motor de máquina de lavar que é acionado quando ligamos uma chave de on-off. Quando ligado, a impressão que temos é do movimento da nave, sobre a tela, colocamos uma guia de madeira, que deve servir para que a aluna possa riscar com um pincel sobre a mesma, fazendo o movimento do pulso luminoso que seria acionado dentro da nave. Na primeira situação, em que o dispositivo está desligado, a aluna faz o risco, simulando a situação do observador Maria do exemplo do livro, que está em repouso dentro da nave, em seguida quando o dispositivo está ligado, a aluna deve novamente fazer outro risco, seguindo o mesmo movimento da situação anterior e nesta circunstância o resultado deve simular a situação verificada pelo observador João, de fora da nave, relacionamos assim a situação em que a tela está em “off” com a situação descrita no exemplo pelo observador Maria, e na situação em “on" pelo observador João. Nas Figura 5 e 6 mostramos o nosso dispositivo em detalhes. 


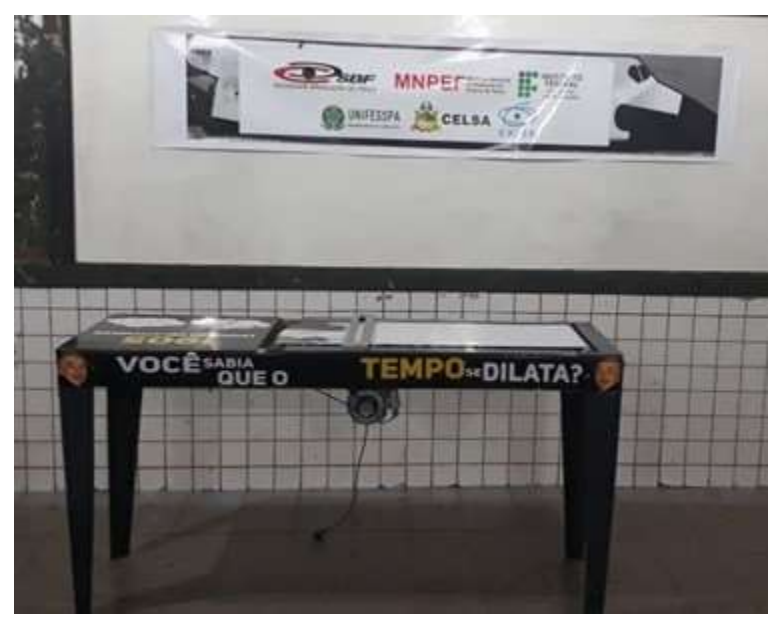

Figura 5: O dispositivo educacional que chamamos de Tela, para exemplificar o conceito de dilatação temporal. Vista de lado. Fonte: Os autores.

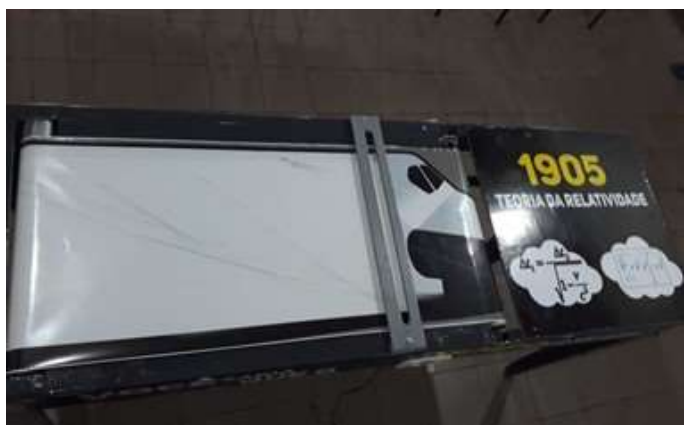

Figura 6: Vista de cima do dispositivo, mostrando a parte que deve ser rabiscada na tela e que deve mostrar a trajetória do pulso luminoso na experiência. Fonte: Os autores.

A relação matemática que correlaciona os intervalos de tempo pode ser deduzida a partir da Figura 4 e é dada por:

$$
\Delta t=\frac{\Delta t_{0}}{\sqrt{1-\left(\frac{v}{c}\right)^{2}}} .
$$

$\mathrm{Na}$ equação acima relacionamos os intervalos de tempo $\Delta t$ e $\Delta t_{0}$, em que $v$ e $c$ são, respectivamente, a velocidade com que o vagão se desloca e a velocidade da luz no vácuo, esta última que corresponde a aproximadamente trezentos mil quilômetros por segundo $(300.000 \mathrm{~km} /$ s).

Este é um experimento lúdico que tem a intenção de provocar no estudante de baixa visão uma compreensão a respeito do conceito de dilatação temporal, de modo que é opcional o uso de cálculos, o professor é claro, pode usar qualquer meio à sua disposição para poder repassar a ideia das medidas, no nosso caso, usamos um pequeno pedaço de TNT, mas poderia ter sido barbante ou mesmo uma régua, desde que observado o tipo de deficiência do estudante, no caso em específico o uso do TNT amarelo, que é encontrado facilmente em lojas de papelaria, foi útil porque era de fácil percepção para a estudante. Usou-se o TNT para medir o comprimento do rabisco na Tela, tanto na condição que simulava o repouso quanto na situação de movimento, atribuindo uma regularidade, como por exemplo, marcando "nós" igualmente espaçados por quatro dedos; atribuindo as medidas à equivalência ou correspondência com o tempo medido por estes observadores João e Maria. Na situação em repouso verifica-se que essa distância corresponderia a um valor de intervalo de tempo que é menor do que a correspondência associada a situação do movimento, pois quando a Tela está em movimento, a ação de rabisco na vertical, resulta uma linha desenhada na diagonal, na sequência usa-se o TNT como medidor deste comprimento, temos que, o resultado é bem maior do que aquele medido na situação de repouso. Fazendo a equivalência destas distâncias com o tempo, verifica-se a compreensão de que o tempo é dilatado por conta do movimento. A seguir mostramos em Figura 7A e 7B a experiência sendo realizada pela aluna. 

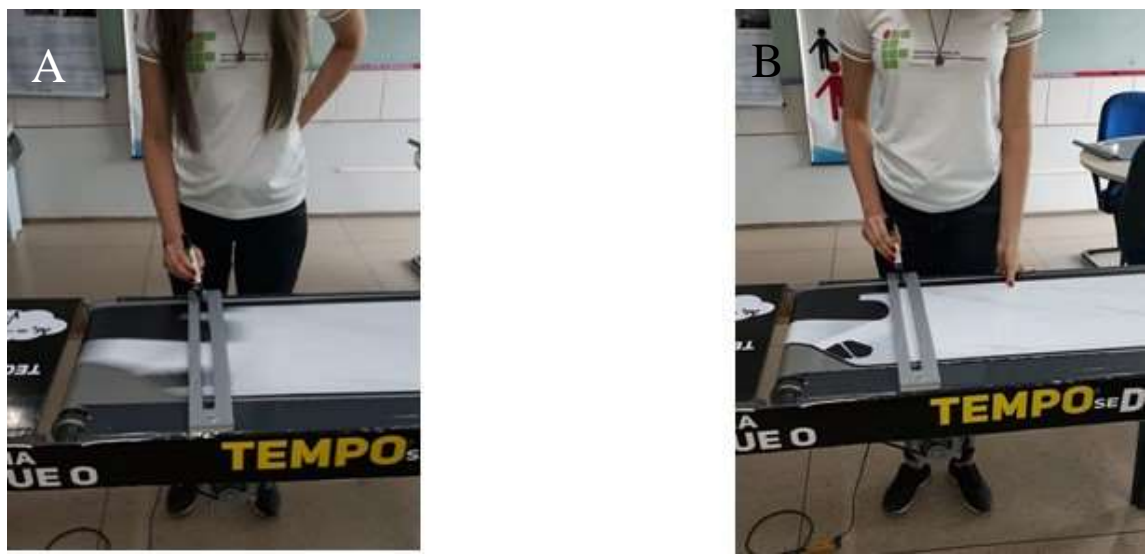

Figura 7: Situação em que a Tela está desligada, simulando a experiência do feixe luminoso dentro da nave ou do trem (A) e a situação mostra o momento em que a Tela está ligada e simula a medida feita pelos observadores que estejam de fora da nave ou do trem (B). Fonte: Os autores.

\subsection{REDE DE CONTRATAÇÃO ESPACIAL}

A medição do comprimento de um corpo que esteja em repouso em nosso referencial pode ser feito facilmente por meio das ferramentas adequadas como régua, trena, mas estes sempre tem pouca precisão, para uma visão macroscópica esta imprecisão é pouco relevante, ademais, para um referencial que se move com velocidade constante e a um valor de velocidade que é muito inferior a velocidade da luz, que é aproximadamente de trezentos mil quilômetros por segundo $(300000 \mathrm{~km} / \mathrm{s})$, qualquer variação na medida por conta deste movimento não deve ser perceptível. No entanto, quando se trata de aferir distâncias ou tamanho de objetos longínquos no espaço sideral é preciso levar em consideração os Efeito da Relatividade.

Vamos exemplificar isso citando o exemplo que é narrado no livro do Halliday et al. (2009) [8]. Considere uma barra de comprimento $L_{0}$ medida pelo observador que está em repouso com a barra, se esta é medida por um observador de fora deste referencial e que se move com relação ao primeiro com velocidade $v$ ao longo da maior dimensão o resultado desta medida é um comprimento $L$, menor, dado por:

$$
L=L_{0} \sqrt{1-\left(\frac{v}{c}\right)^{2}}
$$

O nosso dispositivo para abordar este conceito é chamado de Rede e deve ser capaz de repassar a ideia de contração do espaço. A situação ao qual ele se aplica é descrita a seguir: vamos considerar que o nosso observador Maria esteja em uma nave que viaja em direção a uma estrela bem massiva, tão massiva que a mesma seja capaz de torcer o espaço-tempo em volta da estrela. Maria faz medidas, com sua régua, de uma determinada barra que esteja em repouso em seu referencial. Para o observador João, que está fora da nave e, com seus equipamentos, afere que o comprimento dessa barra é diferente, ligeiramente menor, para isso vamos mostrar o dispositivo nas Figuras 8 e 9: 


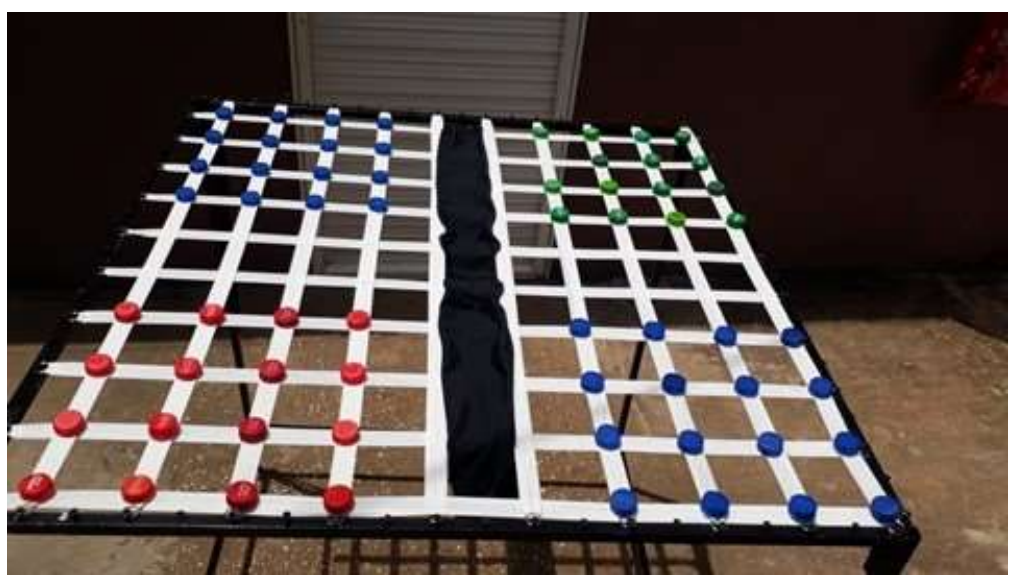

Figura 8: A Rede, montada sob a armação de ferro no formato de uma mesa sem a parte superior, em seu lugar fixas elásticas cruzadas para representar pontos do espaço-tempo e com estes cruzamentos destacamos com as tampinhas de garrafa pet tornando mais visível. Fonte: Os autores.

A Rede foi construída na base de um esqueleto de metal no formato de uma mesa sem a parte superior e no lugar dela fixamos tiras de elástico cruzados, de modo que, os quadrados formados sejam praticamente idênticos, nos pontos de cruzamento colocamos tampinhas de garrafa pet nas cores azul, vermelho e verde, de modo que estas interseções fiquem mais destacadas para o estudante de baixa visão. Na faixa do centro colocamos uma lona preta para que seja depositado um peso de aproximadamente $2,8 \mathrm{~kg}$, o peso tem a mesma cor da faixa, este peso pode representar, no nosso exemplo, qualquer objeto massivo ou com grande concentração energética que possa fazer o papel de uma estrela gigante ou um buraco negro. É preciso definir estes dois exemplos melhor, estrelas gigantes se comparada com o nosso Sol, são estrelas de 10 a 30 vezes superior ao seu tamanho e sua luminosidade varia de 10 a 1000 vezes mais, e um buraco negro é um corpo celeste compacto com incrível densidade comprimido em um espaço relativamente pequeno e geralmente pode ser o estado que a matéria atinge ao sofrer um colapso gravitacional no qual nem a luz, nem a matéria, ou qualquer outro tipo de sinal podem escapar, de acordo com o dicionário astronômico estes termos são bem definidos em Mourão (1987) [9]. Estes entes, que buscamos como exemplos, seriam capazes de torcer o espaço-tempo de modo que a luz ou mesmo uma nave viajando próximo destes corpos poderiam experimentar a influência da curvatura no espaço-tempo provocado por estes corpos. A experiência se dá sob o seguinte raciocínio: Nas bordas da Rede os espaçamentos quadriculados, igualmente espaçados, representariam a situação do observador Maria, que estaria medindo o tamanho da barra em repouso no seu referencial, o tamanho da barra concorda com a distância entre duas Tampinhas de Garrafa Pet (TGP) ao longo de uma linha vertical, esta linha é medida a partir do posicionamento do usuário na Rede, neste caso o posicionamento da aluna (Figura 9).

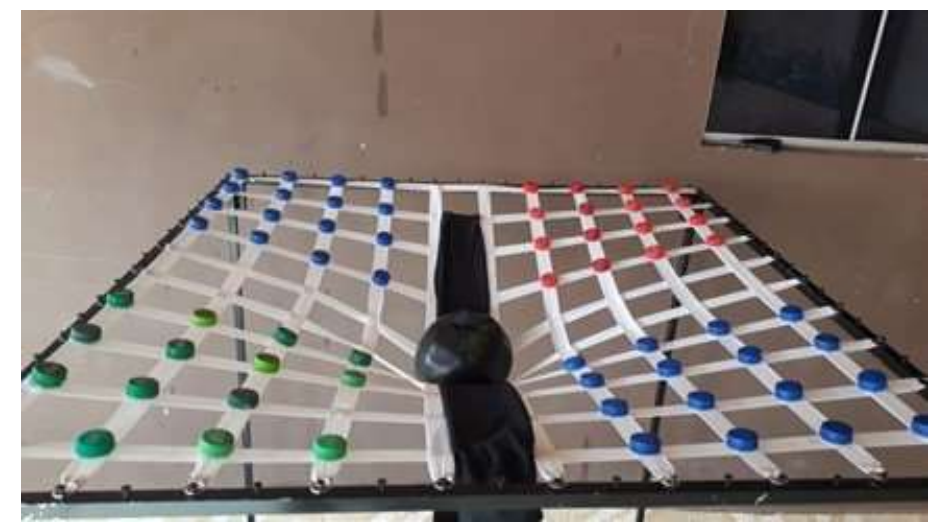

Figura 9: A Rede com um corpo massivo que está sendo representado pela bola no centro. Os cruzamentos são pontos do espaço-tempo representados pelas tampinhas. Fonte: Os autores. 
O leitor pode observar na Figura 9, por exemplo, as tampinhas em azul, principalmente as que estão mais ao centro da Rede, quando vistas por essa vertical, escolhida pela aluna para observar, que estas parecem mais próximas umas das outras e esta seria a situação medida por um observador de fora da nave, que mede o comprimento desta barra. As cores devem ajudar a estudante de baixa visão, perceber esta noção. Esta é ainda uma noção que deve ser mais aperfeiçoada, supõe-se, por exemplo, trocar as TGP's por alguns LED's, para que estas sejam ainda mais provocativas à percepção do(a) aluno(a), na mesmas condições, ou podemos também propor que uma fonte luminosa posta em cima da Rede, figurando assim, em um anteparo logo abaixo da Rede, a projeção dos pontos do espaço-tempo que são representados pelas TGP's. Os pontos dessa projeção seriam marcados com tachinhas e, por conseguinte, medidas as distâncias com TNT, ao fim desta experiência a aluna deve ser capaz de absorver o conceito de contração espacial quando verificado que estas distâncias, desde a borda até ao peso no centro, diminuem.

\subsection{DESCRIÇÃO DO MATERIAL UTILIZADO}

Para a Tela e a Rede vamos descrever o material utilizado e como foi construído, primeiramente a Tela:

- Uma mesa de madeira construída sob encomenda, de comprimento 1,53 m, 0,5m largura e $1,1 \mathrm{~m}$ de altura;

- Um motor de máquina de lavar (potência $0,18 \mathrm{~kW}$ );

- $1 \mathrm{~m}$ de cano de 40;

- Quatro rodas de rolimã;

- Correia de borracha;

- Um interruptor;

- Um Dimmer;

- 22 Parafusos autobrocante $n^{\circ} 8$;

- Guia de compensado $(0,5 \mathrm{~cm} \times 7 \mathrm{~cm} \times 50 \mathrm{~cm})$ para manter a orientação do rabisco feito pela aluna em linha reta.

- Lona para impressão do desenho1,95m x 0,47m

Para a Rede:

- Doze hastes de ferro quadrangulares;

- 80 Parafusos cabeça chata $4,5 \mathrm{~mm}$ e $35 \mathrm{~mm}$;

- Fios de elástico $14 \mathrm{~m}$ x 0,05m (dividir em 20 pedaços de $70 \mathrm{~cm}$ e colocar argolas nas extremidades);

- 40 Argolas (para segurar os elásticos nos parafusos da mesa);

- 64 Tampinhas de diferentes cores de garrafa pet (da cor que mais confortável para o aluno);

- Uma bola de leite cheia de areia e adesivada com fita isolante para ficar totalmente vedada ( massa $=2,8 \mathrm{~kg}$ );

- Um pano para contrastar com o elástico.

\section{RESULTADOS E DISCUSSÃO}

Após o levantamento de reconhecimento do público, constatamos que o número de alunos com deficiência visual na IEF está disposto da seguinte forma, como mostrado na Tabela 1 a seguir. 
Tabela 1: Tabela com o nome dos alunos, curso e grau de estudo na IEF.

\begin{tabular}{cccc}
\hline & \multicolumn{3}{c}{ Números de alunos com deficiência Visual - IEF } \\
\cline { 2 - 4 } $\mathbf{N}^{\mathbf{0}}$ & Aluno & Curso & Grau \\
\hline $\mathbf{0 1}$ & F.B.L. & Meio Ambiente (Integrado) & Ensino Médio \\
$\mathbf{0 2}$ & E.A.C. & Meio Ambiente (Integrado) & Ensino Médio \\
$\mathbf{0 3}$ & L.G.J. & Licenciatura em Química & Superior \\
& & & \\
\hline
\end{tabular}

Apesar da Tabela 1 trazer a informação de mais de um aluno com BV, apenas com uma aluna, foi possível dar continuidade com as atividades propostas neste trabalho, a experiência com a Rede foi muito promissora, e a aluna alcançou o objetivo da proposição deste produto educacional, que era de compreender o conceito de dilatação temporal, afirmamos isso baseado justamente na contagem que a aluna podia fazer dos espaçamentos dos nós feitos numa fita de TNT usada para medir as distâncias rabiscadas na Tela.

A fita de TNT é apenas uma proposta a ser usada pelo professor para ajudar o aluno com BV a compreender as distâncias ou comprimentos realizados no experimento, no caso específico adotouse a fita de TNT fazendo uso dos nós que eram dados na própria fita, a distância entre dois nós era a distância do próprio palmo do aluno, isso ajudaria ao próprio aluno a ter a noção do tamanho. Porém a experiência da Rede ainda ficou um pouco confusa, em parte talvez, por conta da própria deficiência, que trazia a mesma uma limitação para realizar a tarefa, uma vez que a deficiência da aluna impõe a ela um campo visual limitado e por vezes com muita dificuldade de focar por muito tempo a imagem, logo a aluna tinha dificuldade de focar a visão nas tampinhas de garrafa mais próximas do centro, mas mesmo diante da dificuldade a aluna percebeu que os espaçamentos quadriculados da Rede já não mantinham o mesmo padrão de espaçamento regular, quando comparados os espaços da borda com os espaços do centro.

Apresentamos uma proposta educacional para o público de BV que pode dar oportunidade de aprendizado a está temática de Física Moderna, dilatação temporal e contração espacial, que é tão cara, mesmo ao público sem deficiência alguma, mostrado assim que esta proposição metodológica de ensino pode também servir aos dois públicos e traz grande enriquecimento acadêmico, cultural e científico, fazendo uma relação baseada no censo de 2010 [10], este assunto traz experimentos que podem contribuir com o aprendizado de mais de 6 milhões de pessoas, este é o valor estimado pelo dados do censo de 2010 [10] para o número de pessoas com algum grau de deficiente visual, e é o número em potencial de pessoas que podem se interessar pelo tema, mesmo sabendo que nem todos devem ser estudantes ou devem estar em idade escolar. $\mathrm{O}$ trabalho visa fazer ponte a esses dois universos, um universo de conhecimento de teorias avançadas da Física Moderna e o universo de alunos com BV.

Damos a eles uma boa base teórica da física moderna, incipiente nestes tópicos aqui abordados de contração espacial e dilatação temporal, através da adaptação curricular prescrita na Lei de Diretrizes e Bases da Educação - LDB no artigo 59 [11], acreditamos que os experimentos aqui abordados ainda podem ser aperfeiçoados, mesmo tendo sido seguidos com a participação de apenas um única aluna de $\mathrm{BV}$, a metodologia pode ser adaptada a um público bem maior e está em fase de teste esta ampliação, outros aspectos com relação à deficiência da aluna também não foram abordados por não se tratar do foco do trabalho e por essa razão, este também não pode ser considerado um relato de caso sobre a deficiência da aluna. O produto educacional decorrente da aplicação desta metodologia e do material produzido também contou com suporte de uma professora assistente que sempre acompanhou a aluna em todas as atividades e pôde auxilia-la nas eventuais perguntas e medições que se fizessem necessárias a investigação desse trabalho.

\section{AGRADECIMENTOS}

Agradecemos à professora Daniela S. Q. Granhen pela leitura e sugestões, à professora Claudianny Maria Galvão, que deu auxílio a aluna E. A. C. que fez parte de nossa investigação, à própria aluna E. A. C. que nos permitiu explorar as possibilidades metodológicas de se abordar os temas de Física Moderna com ela e que aqui representou muito bem o público BV, assim como 
suas necessidades no anseio do conhecimento, ao Programa de Pós-Graduação da Faculdade de Física - UNIFESSPA.

\section{REFERÊNCIAS BIBLIOGRÁFICAS}

1. Sturman A. Case study methods, Educational research, methodology, and measurement. An international handbook 2nd. Ed. JP Keeves, Oxford, Pergamon Press; 1997. 61-66p.

2. Coicev W. Cegueira x Baixa Visão, [Internet]. São Paulo: Chevy Optical lens; [acessado em 26 Fev 2019]. Disponível: https://www.subnormalvision.com.br/cegueira-baixa-visao.

3. Conde AJM. Definindo a Cegueira e a visão subnormal, [internet], Rio de Janeiro: Instituto Benjamin Constant; 2005 [acessado em $26 \quad$ Fev 2019]. Disponível: http://www.ibc.gov.br/images/conteudo/AREAS_ESPECIAIS/CEGUEIRA_E_BAIXA_VISAO/ARTI GOS/Def-de-cegueira-e-baixa-viso.pdf.

4. Domingues C de A, Sá ED, Carvalho SHR, Arruda SMCP, Simão VS. Os Alunos com Deficiência Visual: Baixa Visão e Cegueira, Coleção A Educação Especial na Perspectiva da Inclusão Escolar, 2010.

5. Soranz JF, Wada D, Chimello AM, Gozzano MCC, Quevedo RN, Cassago R, Morelli RF. Retinose pigmentar: relato de caso. Rev Fac Ciênc Méd Sorocaba. 2016. Out;18(22).

6. Tayah D, Angelucci RI, Sampaio P, Rehder JRCL. Retinose Pigmentar, Arq. Med. ABC. 2004 dez.;29:8286.

7. Furtado CM, Móvio MI, Nishio LHE, Walter LT, Kihara AH. Um olhar sobre a retinose pigmentar. Nanocell News. 2015;3(2):3-11. doi: 10.15729/nanocellnews.2015.11.03.001

8. Halliday D, Resnick R, Walker J. Fundamentos de Física, volume 4: óptica e física moderna. Tradução e revisão Ronaldo Sergio de Biasi, Rio de Janeiro: LTC, 2009. $8^{\mathrm{a}}$. edição.

9. Mourão, R.R. de F. Dicionário Enciclopédico de Astronomia e Astronáutica, Editora Nova Fronteira S. A., Rio de Janeiro, 1987.

10. IBGE. Censo demográfico 2010 - características gerais da população, religião e pessoas com deficiência, Censo Demográfico, Rio de Janeiro, 2010.

11. Brasil, lei no 9.394, de 20 de dezembro de 1996, 20 Dezembro 1996. [Internet]. Brasília-DF, Presidência da República; 1996. Disponível: http://www.planalto.gov.br/ccivil_03/Leis/L9394.htm. 